\title{
Seventh Hypertension Research Award for authors of outstanding papers in Hypertension Research
}

Hypertension Research (2017) 40, 105-106; doi:10.1038/hr.2016.150

J Tapanese Society of Hypertension (JSH) has announced the winners of the seventh Hypertension Research Award at the 39th Annual Scientific Meeting held on 30 September to 2 October, 2016 in Sendai, Miyagi, Japan. This award was established in 2010 to recognize significant contributions of researchers to the advancement of researches in hypertension and related studies. Among the first or main authors of the articles published in Hypertension Research, official journal of JSH, from April 2015 (Vol. 38, No. 4) to March 2016 (Vol. 39, No. 3), the journal's editorial committee members selected the following winners.

\section{HYPERTENSION RESEARCH AWARD OF EXCELLENCE}

Dr Noriyuki Iwama, Department of Obstetrics and Gynecology, Tohoku University, Sendai, Japan.

For contribution of 'Maternal clinic and home blood pressure measurements during pregnancy and infant birth weight: the BOSHI study.' Vol. 39, No. 3, pp 151-157.

http://www.nature.com/hr/journal/v39/n3/full/hr2015108a.html

This prospective cohort study demonstrated that home blood pressure monitoring is better predictive of neonatal birth weight than office blood pressure in pregnant women.

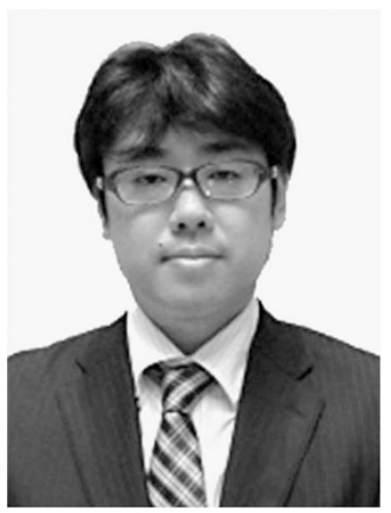

Dr Noriyuki Iwama

\section{HYPERTENSION RESEARCH AWARD}

Dr Masato Nagai, Radiation Medical Science Center for Fukushima Health Management Survey, Fukushima Medical University, Fukushima, Japan.

For contribution of 'Secular trends of the impact of overweight and obesity on hypertension in Japan, 1980-2010.' Vol. 38, No. 11, pp 790-795.

http://www.nature.com/hr/journal/v38/n11/full/hr201581a.html

The authors examined trends of the association between overweight and hypertension for 30 years in Japanese subjects and pointed out that the impact of obesity on hypertension has been grown in these decades.

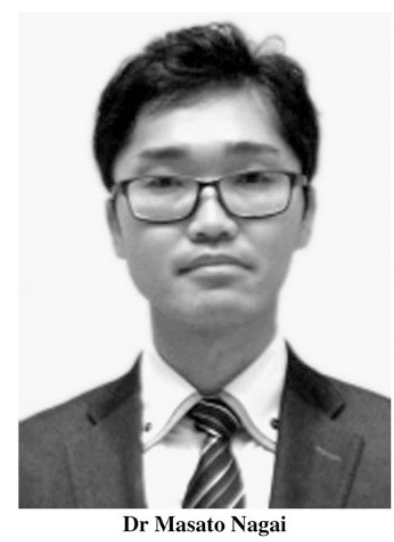




\section{HYPERTENSION RESEARCH AWARD}

Dr Tadaaki Nakashima, Department of Medicine and Clinical Science, Yamaguchi University Graduate School of Medicine, Yamaguchi, Japan.

For contribution of 'TLR4 is a critical regulator of angiotensin II-induced vascular remodeling: the roles of extracellular SOD and NADPH oxidase.' Vol. 38, No. 10, pp 649-655.

http://www.nature.com/hr/journal/v38/n10/full/hr201555a.html In this in vivo experimental study using genetically modified mouse model, the authors indicated that the Toll-like receptor 4 mediates angiotensin II-induced production of reactive oxygen species that promote remodeling of the vascular wall.

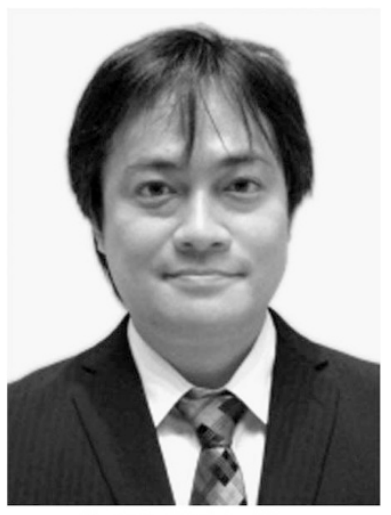

Dr Tadaaki Nakashima

Toshihiko Ishimitsu

Editor-in-Chief,

Hypertension Research 